\title{
Colored asphalt and street print are decorating paving in public spaces
}

\author{
Khawla Kawther* \\ Department of Building and Construction Engineering, University of Technology, Baghdad, Iraq
}

\begin{abstract}
Asphalt is the main material used to finish the internal and external streets of cities. Newly emerged in some countries, the use of colors which is added to the asphalt, it would be possible to use in the paving of this material widely in walking pavements, bicycle paths, parks and open spaces. By analyzing the international experiences as well as practical study, by a survey that was done by Iraqi professors in the specialized field of civil and road engineering, as well as architects, urban designer, and landscapers. Nonproliferation of Colored Asphalt and Street Print applications locally, this application has not been used in Iraq till now. There is a lack of knowledge on this subject, hence, the studies and research need to be carried out on this aspect, and find out their suitability for the local environment. The reasons that it is not used in Iraq are: cost of devices, staff, lack of experience, unavailability of materials, laws - culture- traffic engineering and lack of desire for development. It was found that, it is necessary to legislate engineering laws related to traffic engineering and educate vehicle owners about this new culture.
\end{abstract}

\section{Introduction}

Asphalt applications are very effective in residential and commercial evolution. Through colored asphalts can be obtained texture and style, as well as add safety on the roads, adding architectural and aesthetic values, less expensive than Al-Muqarnas, natural stone or other types of industrial flooring, changing the color of road surfaces reduces the temperature in urban areas.

There are two types to get the colored asphalt paving in Public Spaces; Colored Asphalt and Street Print. The colors can be added to the mixture of asphalt during the process of making, or decoration can be done during the tiling process, or the work of decoration can be done after the tiling process. There are many methods to get colored asphalt, using colorful aggregates, recycled glass, iron, slag, through these red, brown yellow, orange and green colors can be obtained in colored asphalt, and it can also add various colors to asphalt through the cladding of surface material, such as printing on the streets. These materials break through the gaps and act as adhesives to the asphalt.

In the 1990's, Highway Safety Research Center - North Carolina University was tested with color options for bike lane identification in Portland city, their study provided a broad analysis of material durability. These aspects are summarized in Table1.

\section{Colored asphalt}

Colored asphalt is used in many urban areas around the world to define bus and bicycle lanes. Such as London, New York, Auckland, Ottawa, and, Sydney, all of these cities were marked with bus corridors. See Figure 1. [1]

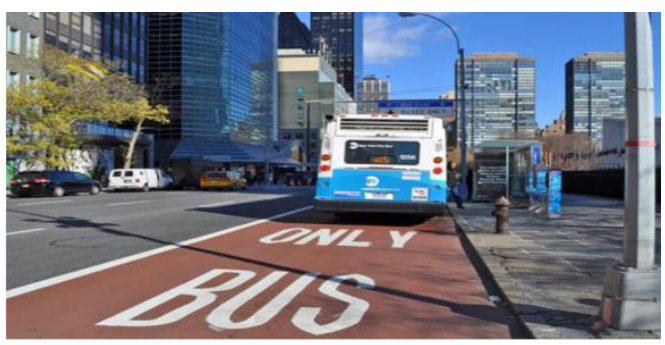

Fig. 1. Red bus lane Colored asphalt Manhattan -United States / W. Carry, (2012).

Their researchers expected that the most durable solution would be a dyed asphalt-wearing course; however, this was not tested, the implementation cost in Portland installed test sections of painted and thermoplastic colors and found that while the painted material wore off after the first winter, the thermoplastic proved to still be in good condition after one year". [2]

The asphalt uses have many benefits، but the black color can sometimes give a bad impression, Color asphalt was produced as an alternative to black asphalt in 1992. The new product is aesthetically pleasing also it maintains the asphalt qualities that are unparalleled. The new 
product consists of two types, integral color for hot mix and integral color dry sealant mix. The color is added to the hot mix and mixed well, and then mix with the hot asphalt in the factory, Colored asphalt is delivered to the project site after it is fully colored. [3]

Table 1. Material Considerations for the City of Portland's Bike lane coloring research (Birk et al., 1999) [4]

\begin{tabular}{|c|c|c|c|c|}
\hline Material & Known Vendors & $\begin{array}{c}\text { Approximate } \\
\text { Materials Cost }\end{array}$ & Durability & Colors, Availability \\
\hline Paint & $\begin{array}{l}\text { A Local paint supply } \\
\text { stores }\end{array}$ & $\begin{array}{c}\$ .04-\$ .10 / \text { lineal } \\
\text { Foot }\end{array}$ & Poor & Wide variety \\
\hline $\begin{array}{l}\text { Thermo } \\
\text { plastic }\end{array}$ & $\begin{array}{c}\text { Flint Trading } \\
\text { (Premark } \AA) \\
336-475-6600\end{array}$ & $\$ 2.66 /$ sq. ft. & $\begin{array}{c}\text { Good. Withstands } \\
\text { Significant volume \&Turning } \\
\text { movements }\end{array}$ & $\begin{array}{l}\text { Blue, red, } \\
\text { Yellow, white }\end{array}$ \\
\hline $\begin{array}{c}\text { Methyl } \\
\text { Methacrylat } \\
\text { based marking }\end{array}$ & $\begin{array}{c}\text { Morton Traffic } \\
\text { Markings } \\
\text { (Dura Stripe }\left({ }^{\circledR}\right) \\
800-835-3357\end{array}$ & $\begin{array}{c}\$ .50-\$ .60 / \text { lineal } \\
\text { Foot }\end{array}$ & Potentially good & $\begin{array}{c}\text { Yellow, White, } \\
\text { Red }\end{array}$ \\
\hline Cold plastic & $\begin{array}{l}3 \mathrm{M}\left(\text { Stamark }{ }^{\circledR}\right) \\
800-362-3455\end{array}$ & $\$ 4.50$ sq. ft. & $\begin{array}{c}\text { Durable with inlay, not as good } \\
\text { with existing asphalt; } \\
\text { Unlikely to hold up to heavy } \\
\text { turning volumes }\end{array}$ & $\begin{array}{l}\text { Blue, red, yellow. } \\
\text { White }\end{array}$ \\
\hline Dyed asphalt & $\begin{array}{l}\text { Asphacolor }{ }^{\circledR} \\
800-258-7679\end{array}$ & $\begin{array}{l}\text { Very costly. Must apply } \\
\text { fresh, treated asphalt. }\end{array}$ & Excellent & Earth-tones \\
\hline $\begin{array}{l}\text { Imprinted and } \\
\text { sealed asphalt }\end{array}$ & $\begin{array}{c}\text { Integrated Paving } \\
\text { Concepts (Street Print) } \\
800-688-5652\end{array}$ & $\begin{array}{l}\text { Costly. Must } \\
\text { Apply fresh } \\
\text { Asphalt. }\end{array}$ & Unknown & Earth-tones \\
\hline $\begin{array}{l}\text { Colored } \\
\text { acrylic } \\
\text { Coating }\end{array}$ & \begin{tabular}{|c|} 
Traffic Safety \\
Systems (Zebraflex $\left.{ }^{\circledR}\right)$ \\
$407-348-2624$ \\
\end{tabular} & Unknown & Potentially good & $\begin{array}{l}\text { Blue, Green, red, } \\
\text { yellow }\end{array}$ \\
\hline
\end{tabular}




\section{Street print}

"Street Print is an innovative property application approach, means the ground coverage of public space with asphalt decorates, similar to stone, bricks or other materials. Street coloring is done by using special phosphoric pigments, or by adding the dye to the asphalt mix, the goal is to give the function of corridors or spaces and categorize them with different colors, this method may be used for traffic and road engineering to determine traffic density and speed. This style is characterized by flexibility, strength, low cost and high durability.

"It does not need maintenance". See Figure 2. [5]
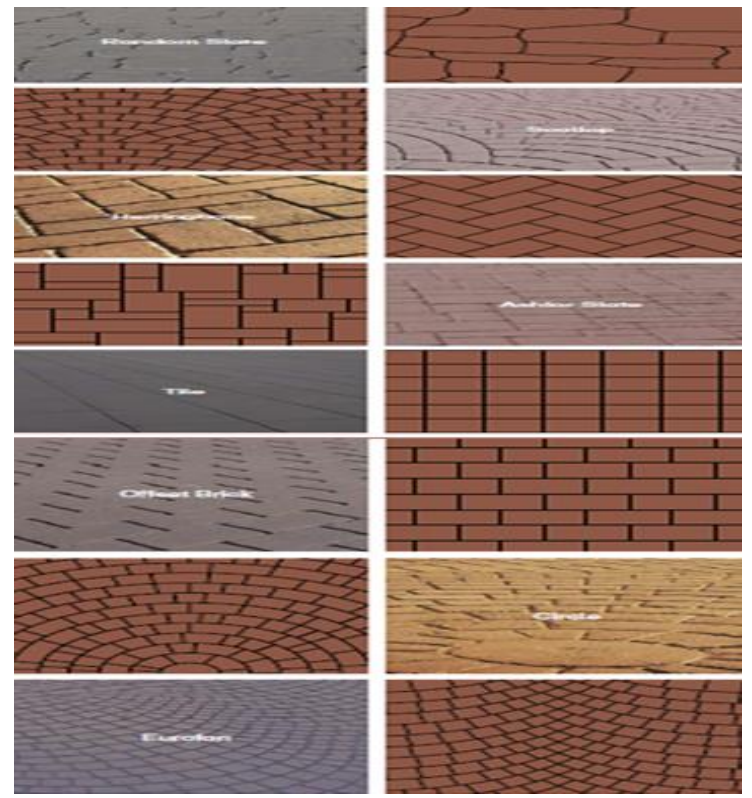

Fig. 2. Different colors \& patterns. http://cjasphaltpaving.com/StreetPrint.pdf.

Street Print Pavement Texturing is " a decorative paving system, which use special templates designed to work on a variety of decorative forms of asphalt the installation of colored pieces on the surface called the connecting of the streets is intended to preserve the surface.In the end decorative architecture pattern will show through repetition form".[6]

"Printing of Street gives multiple possibilities and creativities and enables architects and designers to achieve more with less cost in comparison to brick or stone". See Figure 3. [7]

Printing of Street is fast, easy to be done, needs fewer workers, but requires special equipments for printing and installing decorative paving surfaces. [8]
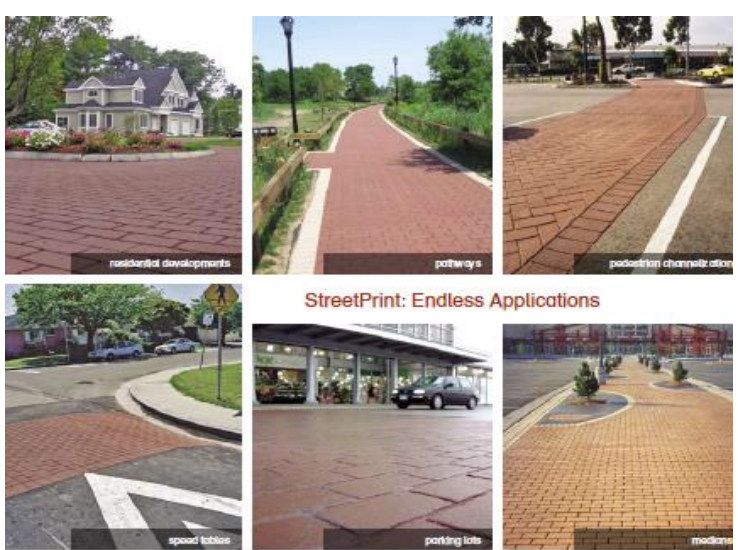

StreetPrint: Endless Applications
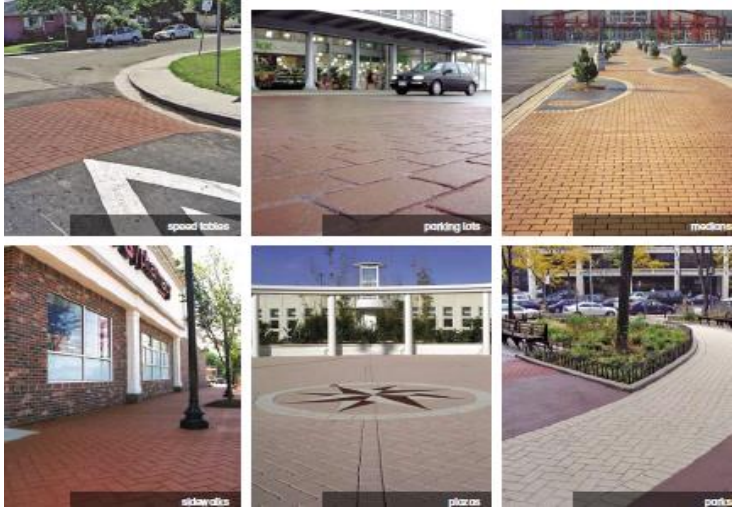

Fig. 3. Application of street print,

http://cjasphaltpaving.com/StreetPrint.pdf.

\subsection{Working steps}

1. Heating the asphalt to SR60 temperature.

2. Printing by Woven Metal Molds on the Streets, the warm asphalt above the ground is pressed using the compressor plate and then lifted.

3. Apply Paint bonds, high performance street using printing by the highway sprayer. See Figure 4 .
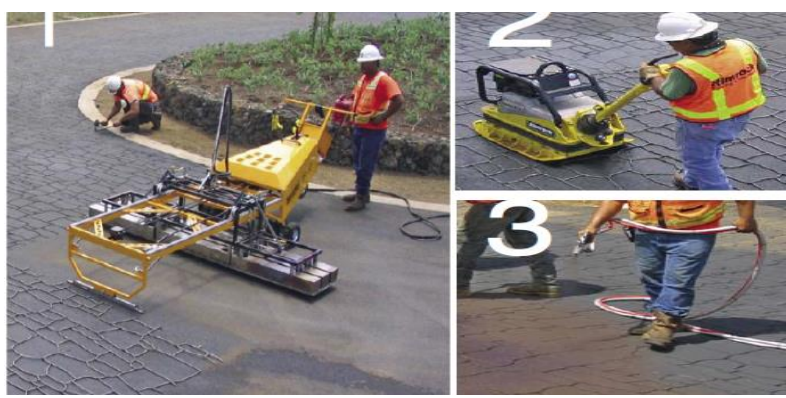

Fig.4. Working method

http://cjasphaltpaving.com/StreetPrint.pdf.

\subsection{Benefits of street printing}

Re-decoration: It can combine a variety of styles and colors, to produce a unique output and interesting designs. See Figure 5.

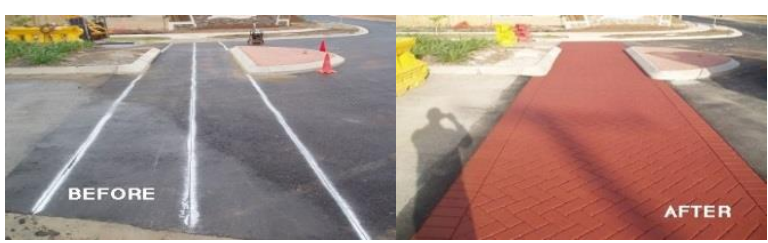

Fig. 5. Benefits of street printing

http://asphaltcementprinting.com/streetprint/WhyStreetPr. 
Endurance: the base of asphalt paving is without joints or layers, so it is preventing the changes that are induced by time, weeds can not grow, its ability to resist various forces and environmental conditions. [9]

Low cost: Methods of effective synthesis, the availability of working costs.

Maintenance: Surface street printing has less maintenance requirements, thus costs less than others. Seamless Repairs: coating systems enable easy repairs to "good as new" condition.

Increase life: Printing street coating systems prevents oxidation and asphalt base immunization which leads to a better appearance, durability. The possibility of creating diversity in design and patterns, the pictures below are some of the examples implemented and their locations: See Figure 6. 7. 8. 9. 10. 11.

\section{Main characteristics}

There are basic properties of architectural paving, that allow to evaluate sidewalk when using of stamped asphalt based on cost, aesthetics, application constraints, and environmental impact.[10]

1. Environmental Factors: Surface materials, unique characteristics and chemical compositions, have different installation; Geography plays a key role in selection for the best user installation [11]

2. Application Factors: downtime, multiple textures, hardness

3. Aesthetic Factors: initial appearance \& design, aesthetic effects of wear \& repair. [12]

4. Cost Factors: Large continuous coverage, cost of printing by concrete costs twice as much as asphalt, according to a tile company, it charges $5.25 \$-6.25 \$$ per sq. ft. While $11 \$$ per sq. foot for printed concrete [13]
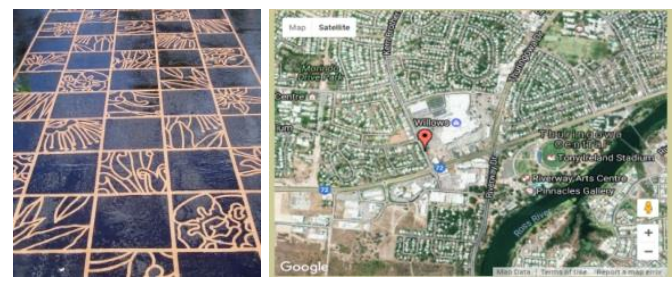

Fig. 6. Pedestrian crossing in Thuringowa- Australia Fig. 7. Kern Bros. Drive, Thuringowa- Australia http://asphaltcementprinting.com/photos/images/acp_p1.j
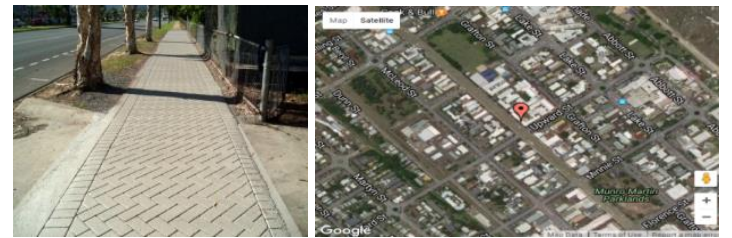

Fig. 8. Footpath outside Cairns, High School http://asphaltcementprinting.com.

Fig. 9. Location of Cairns High School- cairns city http://asphaltcementprinting.com/photos/map10.html.
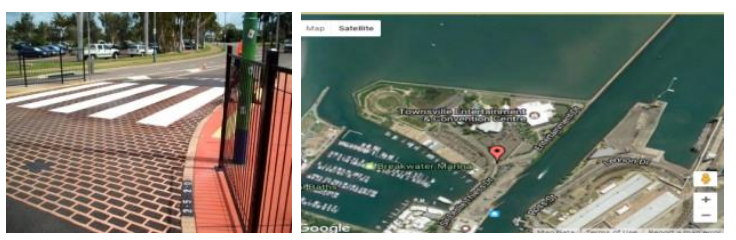

Fig. 10. Pedestrian crossing - Car Parks in Townsville. Fig. 11. location, Townsville City

http://asphaltcementprinting.com/photos/map5.html.

\section{Projects with colored asphalt applications}

\subsection{Dammam, Saudi Arabia}

Dammam city began an experiment in 2016, using colored asphalt, on the main streets of Dammam، a professor and supervisor of traffic safety، at the University of Dammam, stated that asphalt coloring has nothing to do with the power of the vehicle، and that the purpose of using it in Dammam is only aesthetic ' he pointed that the cost of colored exceeded the normal which reduced the chances of using it on a large area and that the coloring should be using pigments that are highly resistant to vehicle movement, and weather conditions. See Figure 12.

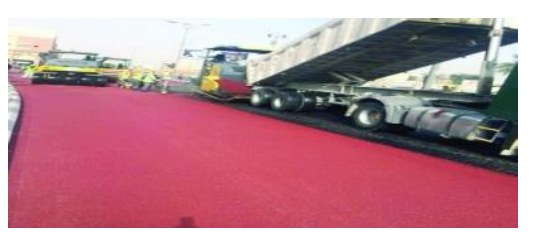

Fig 12. the red asphalt plant in Dammam (Makkah) http://makkahnewspaper.com/article/138757.

He explained that way occupy between $35-50 \%$ of the cities، when the temperature increases, it absorbs heat, and contributes to hot weather. The cold roads work in contrast to $30-50 \%$ of the sun's heat. While drawing that states applicable the red asphalt experience was designed to achieve three objectives; absorb the sun urban heat mitigation' where it can reduce the reflection of the sun's heat to $5 \%$ Beautification of city entrances. Identify specific paths, and distinguish them from the path of vehicles، such as bicycle, bus or pedestrian routes. And select two methods for asphalt coloring:

1. Mixing a chromosome with asphalt material processor to convert it to any color required.

2. Covering black asphalt layer coated with colored material, it is the most widespread method. [14]

\subsection{Streetscapes in Scottsdale, Arizona}

In 2003, municipal officials made the decision to use Street Print, construct, paving $12077.4 \mathrm{~m} 2$ to create, traffic movement domains and urban landscape.[15] The quality of the previous paving influenced in their decisions to use the street printing in a very large project. See Figure 13. 

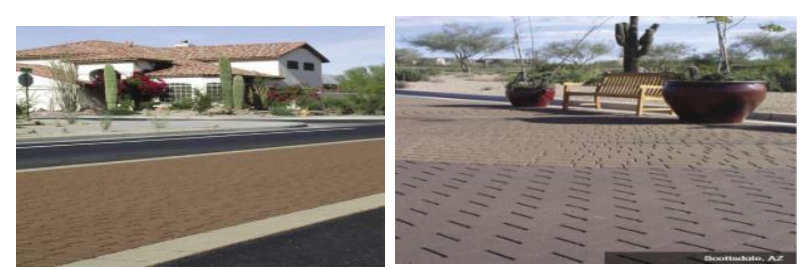

Fig. 13. Streetscapes in Scottsdale, AZ http://www.asphalt-impressions.com.

\subsection{Waterfront revitalization in Toledo, Ohio}

The plot of land in the center of Toledo has been redeveloped; the pavements were paved with unique and beautiful walkways like the cobblestone paths.

Budget constraints made it impossible to choose a handlaid pavers for the $3716.12 \mathrm{~m} 2$ area along the Maumee River. By using Printing of Street the project team was able to replicate the look of brick and cobblestone and completed the project within budget. See Figure 14.

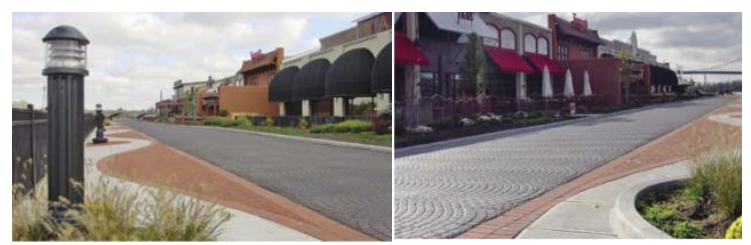

Fig. 14. Waterfront Revitalization, Toledo, $\mathrm{OH}$. http://www.asphalt-impressions.com.

\subsection{Campus at (North Carolina) Greensboro}

Colored asphalt was used to enhance the appearance and image of the campus at the same time capitalizing the low cost of the application of the decorative pavement. The University of North Carolina wanted to find a beautiful image of the campus streets in Greensboro. Chose to print the street to achieve the architectural integrated value therefore of the advantage of the low cost of printing from the street as decorative pavement. The project was $2043.87 \mathrm{~m} 2$ consisting of 9 intersections and 3 corridors. It used Brick Patterns as a statistical style. See Figure 15.

With Printing of Street the University was able to create the unique visual image as well as a fraction of the cost of pavers. $\left[{ }^{16}\right]$

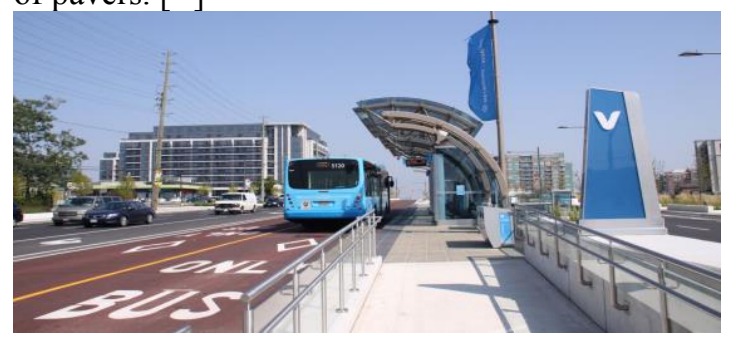

Fig. 18. Bus ways finding -Ontario - S. Varamini, (2016).

Asphalt paving is achieving safe, resistant to environmental conditions, permanent, recyclable, and more economic, as far as maintenance, asphalt is the quickest and easiest to repair, more viable, marketable material. [18] See Figure 19. 20. 21. 22. 23. 24.
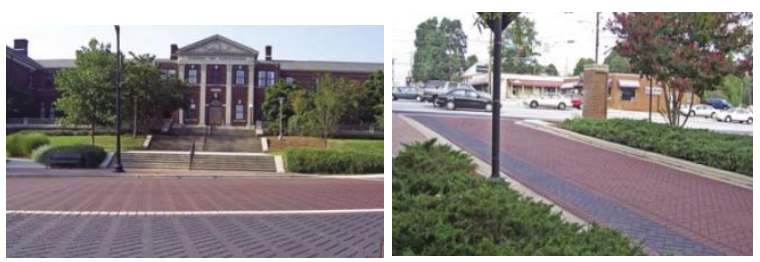

Fig. 15. Campus of the $U$ of NC, Greensboro. http://www.asphalt-impressions.com.

\subsection{New Jersey walkways}

Within the process of urban renewal, which was once the healthy landfill for city waste, $2229.67 \mathrm{~m} 2$ of hiking routes was paved. See Figure 16.

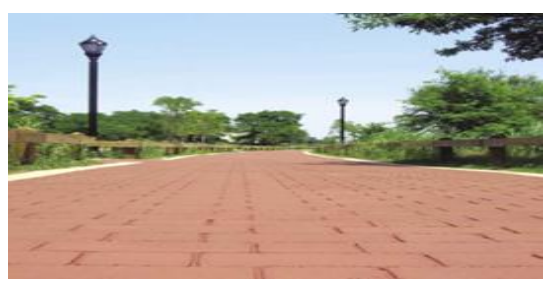

Fig. 16. Walkways for the City of Carteret, NJ

This project is located in the Arthur Hill waterway which leads to the Atlantic Ocean, The workers and technicians needed more than four weeks to complete this application. This project included a park, fishing docks and launch boats.

\section{Advantages of colored asphalt}

Safety: can be achieved easily by using colored asphalt in transportation line, because of the use of colors, it is possible to differentiate between bus corridors, pedestrian paths and bike paths. [17] See Figure 17. 18.

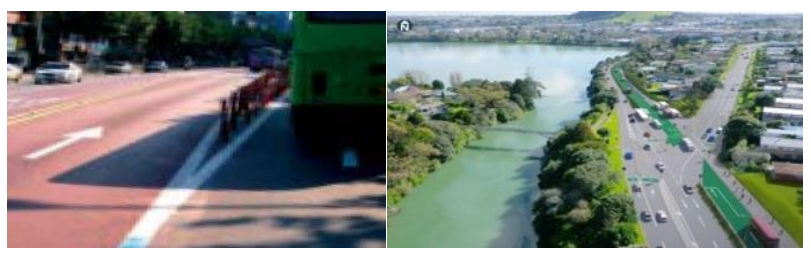

Fig. 17. bus lane in Seoul. Colors help ensure safe connections.

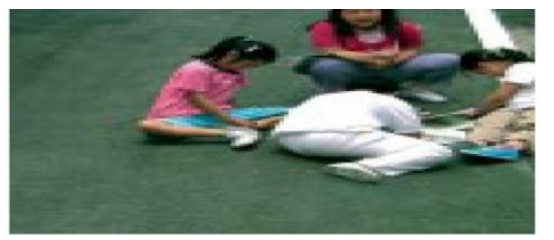

Fig. 19. shapes of light colors. Playground in Seoul. Colors designate safe environments-www.lanxess.com

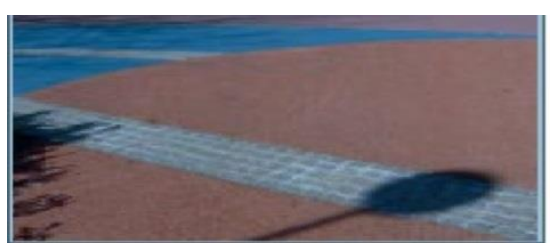


Fig. 20. Pedestrian zone in Marseilles. Gently curving www.lanxess.com

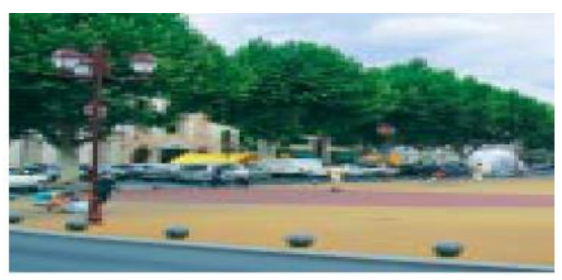

Fig. 21 Marketplace in Ales. Open space and meeting point with South-of-France charm. www.lanxess.com

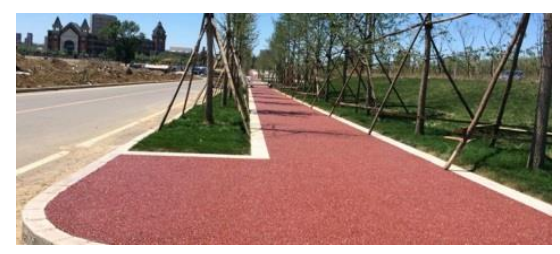

Fig. 22. Determination of directivity

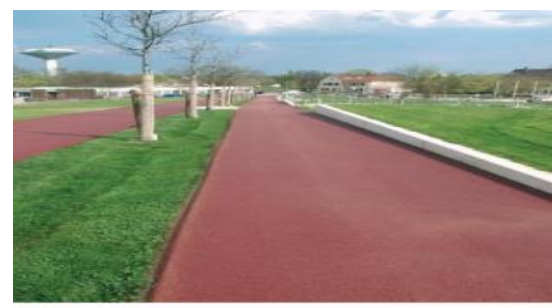

Fig. 23. State Garden shows r. $_{\text {o }}$ in Leverkusen: on colored trails through a world of fascination. www.lanxess.com

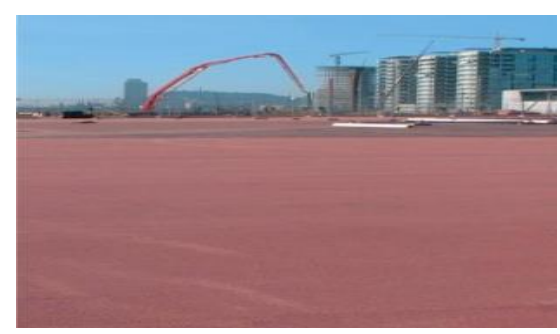

Fig. 24. "Forum" exhibition Adding color and cultural center in Barcelona. Color lends character to open spaces. www.lanxess.com

While it may be the beginning to get colored streets instead of blacks and grays, researchers at the US Department of Energy's "Berkeley Lab" laboratory has been trying to change the color of road surfaces to reduce urban temperatures. See Figure 25. 26.

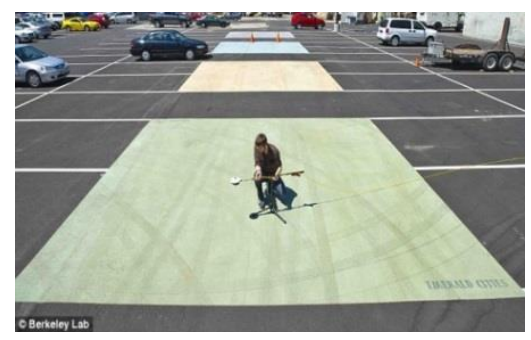

Fig. 25. Lawrence Berkeley National Laboratory, Cold pavement, Case study, Researcher, J. Woods, Works on measuring Levels of solar reflection

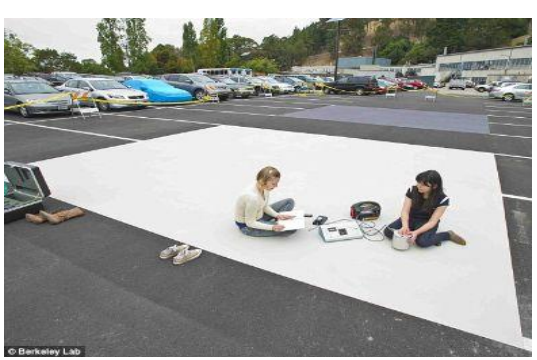

Fig. 26. Device, White counter. Credit Lawrence Berkeley National Laboratory War Over Cool Pavements Heats Up, 21/3/2014 - LAM Staff, by Arthur Allen https://landscapearchitecturemagazine.org/2014/03/21/warover-cool-pavements-heats-up/.

The researchers have devised grounds work the same refrigeration ceiling theory keep the air indoor cold by reverse sun rays ' cold working ways unlike $30-50 \%$ of the heat of the sun compared to $5 \%$ reflected by new asphalt and $10-20 \%$ is reflected by old asphalt.

Currently the research group is working (Hit Island Group) on the conversion of a sector from the parking space of new temporary vehicles in the laboratory "Birklly Lab" to refrigerated floors to review its work, assess their effectiveness over time, The arena will provide an opportunity to test a range of coatings, which is placed directly on the cobbled surfaces [19]

There are many companies specialized in colored asphalt produce and develop of colored powder and strengthening pluralism copolymer synthetic resin emulsion liquid preparation, it has lasting and rich colors, excellent performance, longer life and the construction more convenient, inexpensive, both can improve the physical characteristics of asphalt pavement (with sufficient mechanical strength, a certain flexibility and ability to wake up deformation), dust, easy to clean and wash, easy maintenance and other characteristics, but also improve the ordinary black asphalt pavement monotony, with the surrounding public spaces with each other, coordination, more suitable for construction applications in the city. [20]

Colored Asphalt product used for the "new green building materials" than the bleaching of color asphalt healthier and environmentally friendly.

Specific applications in urban streets, squares, scenic areas, parks and tourist attractions such as roads may be by Colored Asphalt.

Some product of colored asphalt is a color enhancement powder and special multi-copolymer resin emulsion in the field with an electric mixer to fully stir into the slurry, the slurry will be poured into a good mixture of ordinary black asphalt pavement to be paved with a special scraper Evenly spread, shop scraping the thickness of control in 2-3 mm, flat surface, 24 hours after the surface layer of brushing protective agent, beautiful color asphalt pavement can be presented in front.

\section{Practical study}

To measure Available possibilities, The survey was done by the Iraqi professors in the specialization field of 
Civil Engineering and road engineers, because they are dealing with the uses of asphalt in paving, as well as architects, urban designer, and landscaper, where 40 engineers were interviewed،the questionnaire survey was prepared and its objective were based on the hypotheses of this study, in order to prove those assumptions، analysis، and try to propose appropriate solutions ‘ and to indicate the relationship between available resources، and appropriate alternative.

- At first data like gender, certificate, specialization, experience were collected: The results were as follows. See Figure 27. 28. 29. 30

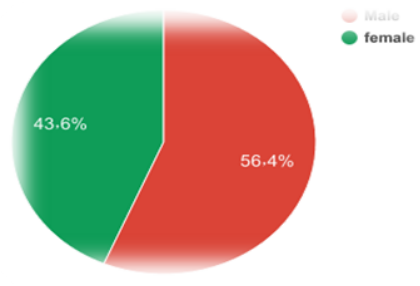

Fig. 27. The Gender

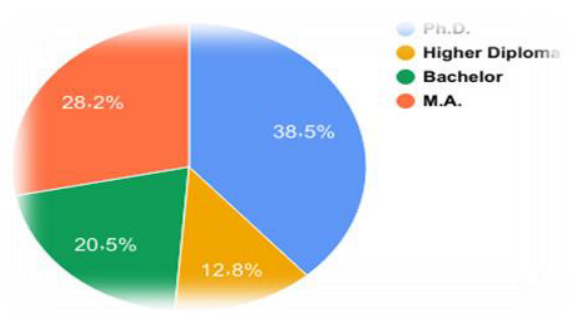

Fig. 28. Certificate

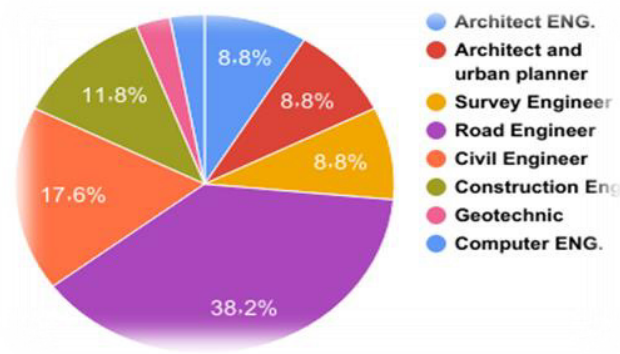

Fig. 29. Specialization

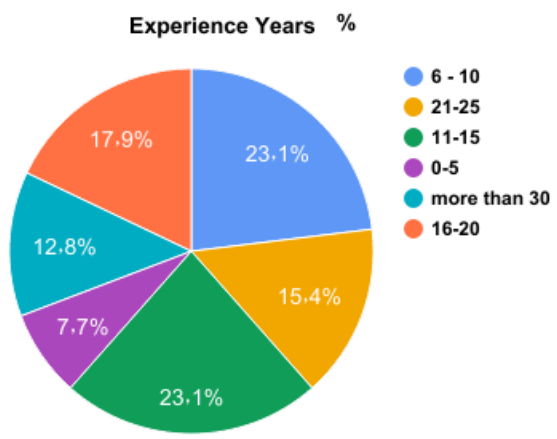

Fig. 30. Experience Years

The best building material used for (open space pavement), Paving by colored asphalt with decorations $22.5 \%$, Paving by colored asphalt without decorations $20 \%$, see Figure 31 .

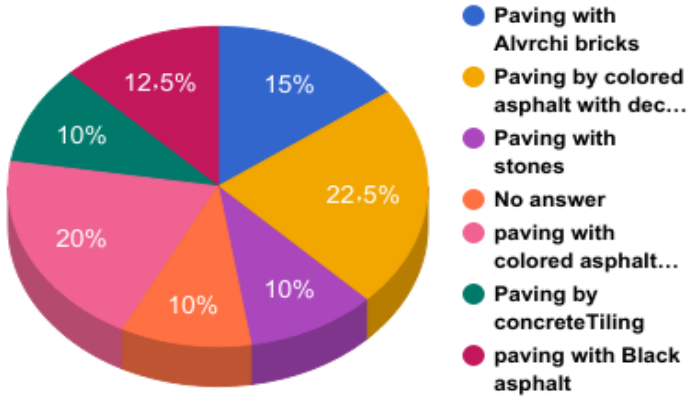

Fig. 31. best building material used for (open space paving)

* The extent of knowledge about colored asphalt applications only $17.9 \%$ they know, see Figure 32 .

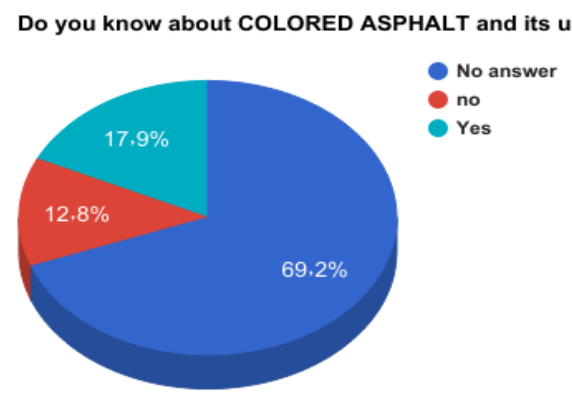

Fig. 32. Knowledge about colored asphalt.

* Only 25\% they know Street Print applications, see Figure 33. this application not used in Iraq till now. See Figure 34. 35.

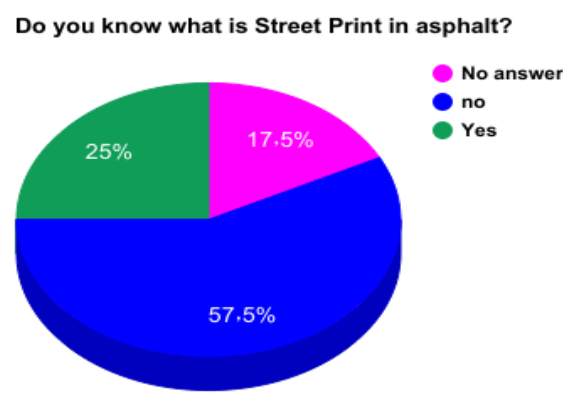

Fig. 33. Knowledge about Street Print.

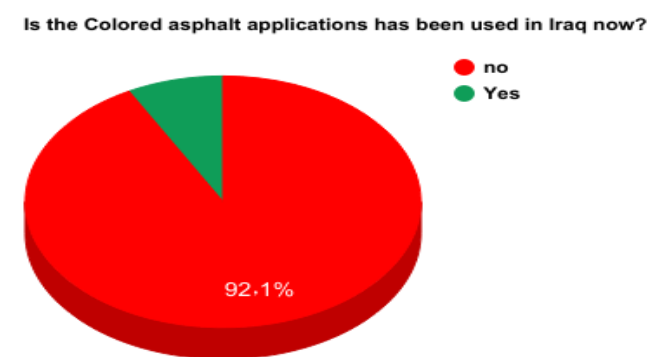

Fig. 34. Colored asphalt not available in Iraq 


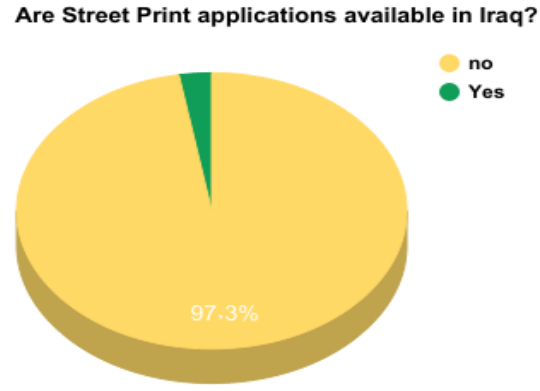

Fig. 35. street print not available in Iraq

* The meaning of street print by asphalt:

When asked about what street print means to the Engineers in this survey, the percentage of responses was $25.6 \%$, see Figure 36. their answers were as follows:

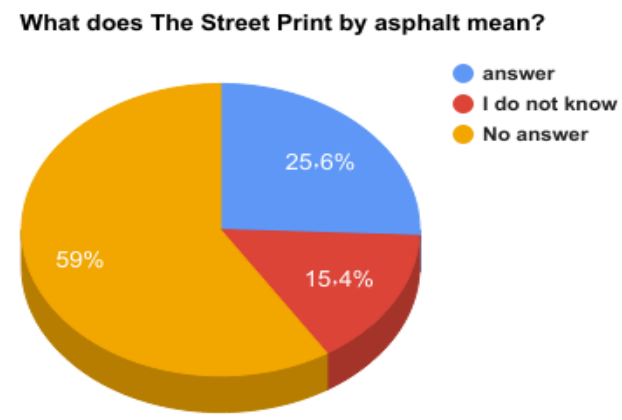

Fig. 36. The meaning of the street print

- Make decorations on asphalt no scratches similar to stone or bricks or other materials.

- It means a street covered with asphalt.

- Street coloring using special phosphoric pigments, or add the dye to the asphalt mix, The goal is to give the function of corridors or spaces and categorized them with different colors. This method may be used for traffic and road engineering to determine traffic density and speed.

- Adding different paints and colors, not an aesthetic addition to the paving, or may mean a name for a particular region or for a particular effectiveness, or may be added by different colors and this adds aesthetic and vitality and joy.

- Use engravings and colors to decorate the forms of paving asphalt.

- Using colored asphalt mixtures.

- The meaning of street printing is the work of two or three-dimensional graphics. The correct term is street coloring, which means the work of a specific and distinctive road surface layer (including concrete paving and asphalt) by adding dyes, or materials colored or additions that cause the paving surface to appear in a certain color after execution.

- Changing the street color with other colors for safety purposes and traffic regulation.

- Making decorations on the street, work in different forms and patterns.

* The best color which is preferred less absorption of heat is an important consideration:

Depending on the location of use of the road, white can be used in some methods, flexible pavement, and lowspeed, and high-load, while the yellow color is preferred to distinguish the corridors of some roads, and determine their use, it was for buses, bicycles or pedestrians, it is not preferable to use white. For foreign expressways, because it causes a high reflection of the light that coming cars from the opposite direction and it can result in serious conditions, if the process of blocking those lights is not observed from the other direction. See Figure37.

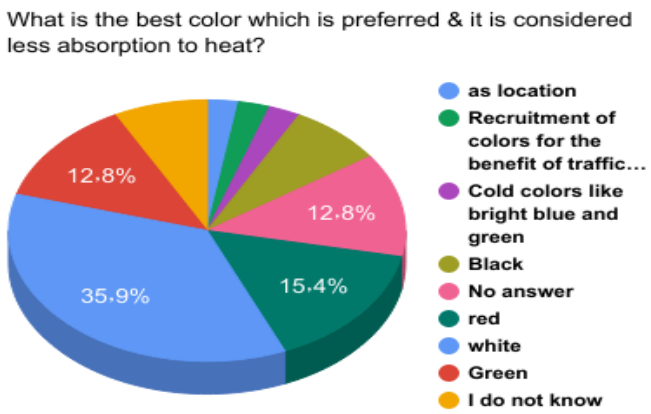

Fig. 37. best color- less absorption of heat.

The methods to add colors to asphalt emulsions: Various answers: see Figure 38.

- There are specialized companies in this field

- During the manufacture of asphalt mix by adding it to the prime coat, it is a collection of compositions that are not mixed with each other.

- Add colors to the asphalt emulsions as desired and available.

- After the paving process, it can add color to the roads or you can also, Add color during the mixing process.

- During the mixing process asphalt, add certain materials.

- There are many aspects on which the desired color depends First, on the type of paving, (Solid or flexible), Second, in addition to the time period required, to resist atmospheric factors, and climate change and weather (rain, snow, temperature, etc.)

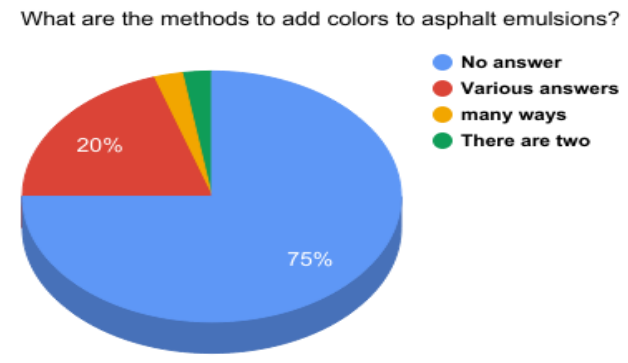

Fig. 38. Various methods to add colors

* Adding colors increases safety. See Figure 39. 
Do you think colors adding increases safety?

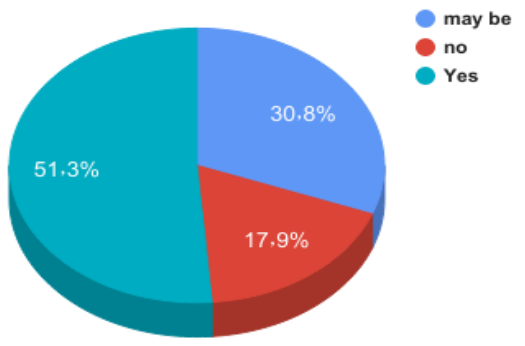

Fig. 39. Colors, adding increases safety

* There is a relationship between the colors and city temperatures that the colors increase temperature. See Figure 40.

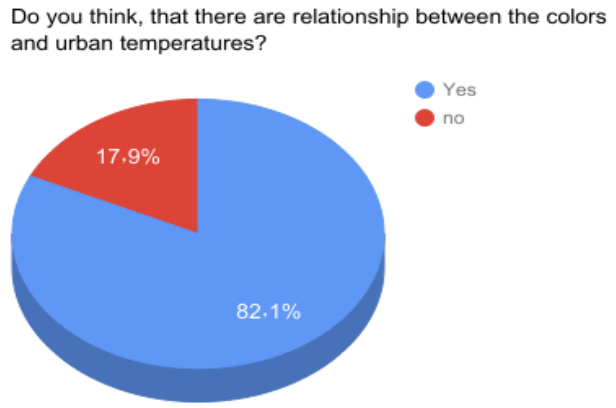

Fig. 40. Colors decreased temperature

* There are refrigerant colored and asphalt surface treatment \& floors cooling, see Figure 41.

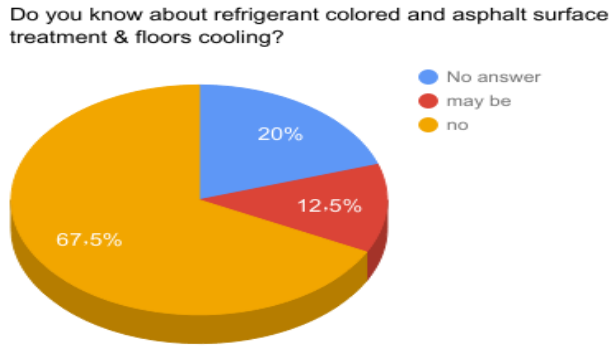

Fig. 41. Knowledge about refrigerant colored

* Using colors in order to determine the type of passing vehicles, such as a designated bus street, another passage for small vehicles and so on. See Figure 42.

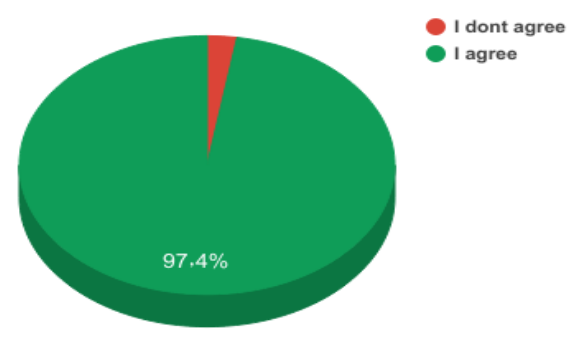

Fig. 42. Colors \& type of passing

* The relationship between the road lighting and the colors used for the ground, see Figure 43.

* Solar heat effect on the color of asphalt, negatively, see figure 44 .

* Pavement materials which are less expensive locally in Iraq), see Figure 45. relationship between the road lighting and the colors

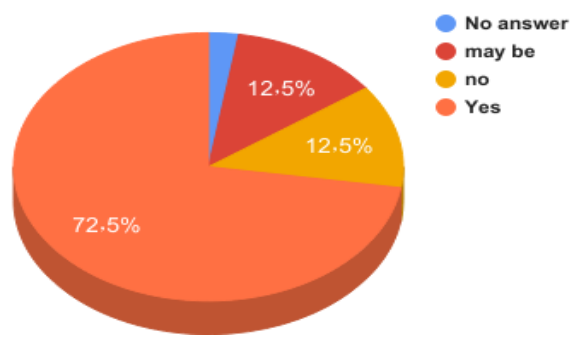

Fig. 43. Colors \& road lighting

Does solar heat negatively affect the color of asphalt?

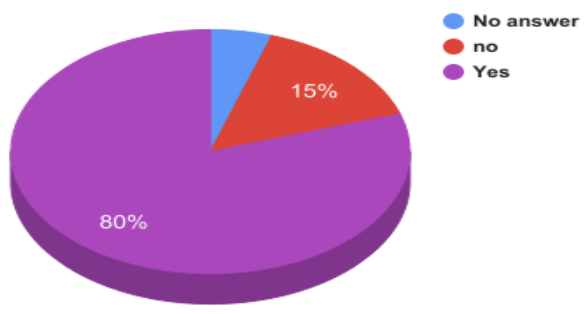

Fig. 44. Lighting \& Solar heat effect

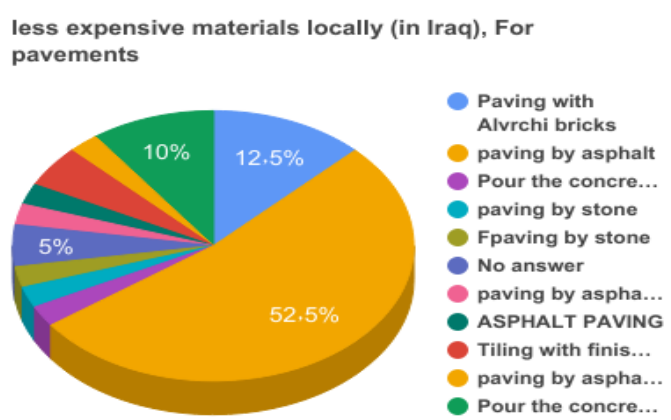

Fig. 45. Less expensive Pavements Materials

* The best material properties of water absorption in paving, flooring in public spaces:

* To resist the absorption of water and should not reduce the permeability of black asphalt or stained (can be used as a type of no pigment or materials and no colored spaces that increase the resistance of water permeability), if it is intended, no more preferred in terms of speed of discharge and permeability within the layer and the stone is the best, see Figure 46.

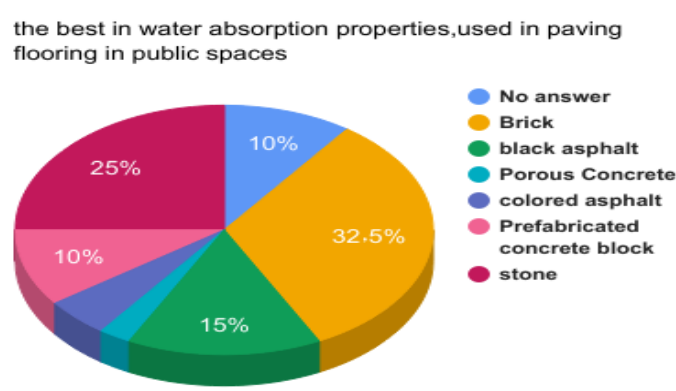

Fig. 46. Water absorption Properties

* The Rain changes the asphalt color negatively, see Figure 47. 


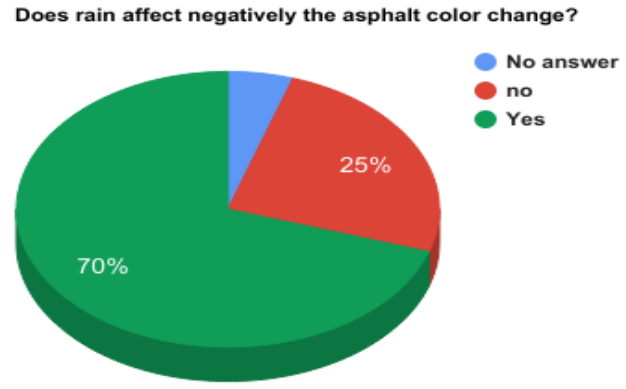

Fig. 47. Rain Effects

- The rough texture is more preferred in the floors of public spaces on this basis, the asphalt $32.5 \%$ and the stone $32.5 \%$, the best floor surfaces, see Figure 48 .

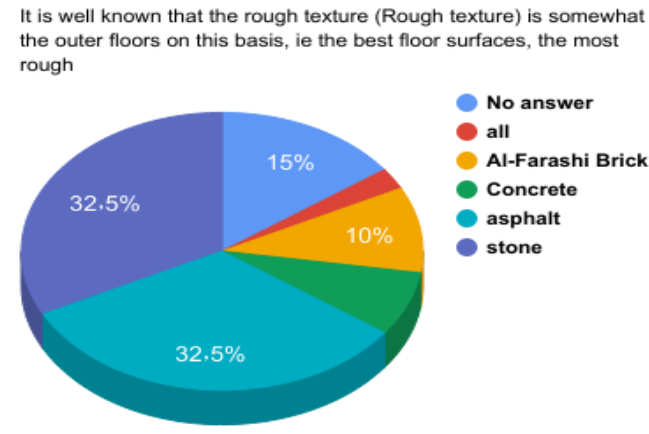

Fig. 48. Best material as a texture

* The reasons that color asphalt is isn't in Iraq, see Figure 49.

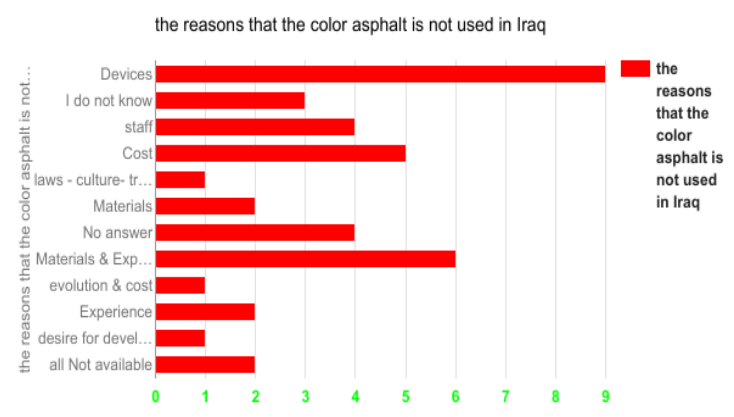

Fig. 49. The reasons that color asphalt is not used in Iraq

* Reasons that street print isn't used in Iraq see Figure 50 .

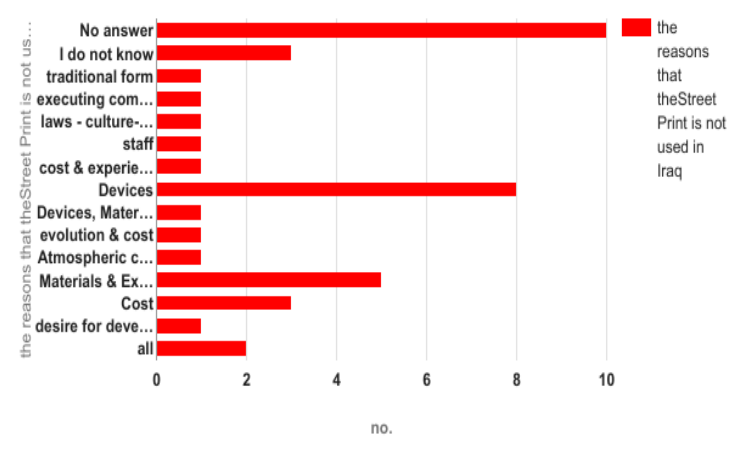

Fig. 50. The reasons that street print is not used in Iraq.

* Before using colored asphalt, it is necessary to legislate laws and engineering equations related to traffic engineering and educate vehicle owners about this new culture.

* There is not enough awareness among the majority of citizens about this new development, because it is essential to provide road services and infrastructure, to educate the citizen before thinking about applying such methods.

\section{Conclusions}

- It is necessary to legislate laws and engineering equations related to traffic engineering and educate vehicle owners about this new culture.

- The majority of citizens is not aware about this new development, it is essential to provide road services and infrastructure, to serve the citizens.

- Colored Asphalt and Street Print has not been used locally in Iraq until now, there is a lack of knowledge on this subject, the need to provide studies and research on this aspect, and find out their suitability for the local environment

- The best building material used for pavement of open spaces, is Paved with colored asphalt with decorations.

The definition of street print by asphalt:

- Means: street covered with asphalt, using colored asphalt mixtures.

- Making decorations on asphalt that are similar to stone or bricks or other materials.

- Street coloring using special phosphoric pigments, or adding the dye to the asphalt mix, the goal is to give the function of corridors or spaces and categorize by color. This method may be used for traffic and road engineering to determine traffic density and speed.

- Adding different paints and colors, is not an aesthetic addition to the paving, or may mean a name for a particular region or for a particular effectiveness, or may be added by different colors and this adds aesthetic, vitality and joy.

- Use engravings and colors to decorate the form of paving asphalt.

- The meaning of street printing is the work of two or three-dimensional graphics. The correct term is street coloring, which means the work of a specific and distinctive road surface layer (including concrete paving and asphalt) by adding dyes, or colored materials or additions that cause the paving surface to appear in a certain color after execution.

- Change the street color with other colors for safety purposes and traffic regulation.

- Making decorations on the street, work in different forms and patterns.

- The best color which is preferred \& considered is the one which absorbs less heat:

- Depending on the location of the road, white can be used in some methods, flexible pavement, and lowspeed, and high-load. While the yellow color is preferred, in distinguishing the corridors of some roads, and determine their use, it was used for buses, bicycles or pedestrians. It is not preferable to use 
white, for foreign expressways, because it causes a high reflection of lights of cars coming from the opposite direction, therefore it is very dangerous.

- The methods to add colors to asphalt emulsions:

- There are specialized companies in this field, during the manufacturing of asphalt mix the colors by adding it to the prime coat.

- During the mixing process asphalt, add certain materials.

- Add colors to the asphalt emulsions as desired and available.

- After the paving process, we can add color to the roads or you can also, add color during the mixing process.

- After the paving process, it can add color to the roads or you can also, add color during the mixing process.

- There are many methods, of which depends on the desired color, First, based on the type of paving, (Solid or flexible), Second, in addition to the time period required, to resist atmospheric factors, and climate change, weather (rain, snow, temperature, etc.)

- Adding colors increases safety.

- Colors \& types of passings: using colors in order to determine the type of passing vehicles such as a designated bus street, another passage of small motor vehicles and so on. There is the relationship between the colors and city temperature, some colors can increase the temperature.

- There are refrigerant colored and asphalt surface treatment \& floors cooling.

- There is a relationship between the road lighting and the colors used for the ground.

- Solar heat affects the color of asphalt, negatively.

- It may be beginning to get colored streets instead of blacks and grays, change the color of road surfaces to reduce urban temperatures.

- Pavement materials of asphalt are less expensive locally (in Iraq).

- The best properties of the material considering its water absorption in paving, flooring in public spaces:

- Resist the absorption of water and do not reduce the permeability of black and colored asphalt, if it is intended, no more preferred in terms of speed of discharge and permeability within the layer and the stone is the best.

- Rain change the asphalt color negatively.

- The rough texture is more preferred in public spaces' floors based on this both the asphalt and the stones are preferred

* The reasons that color asphalt \& street print is not used in Iraq:

- Devices not available

- Staff not available

- The cost

- Laws - culture- traffic engineering

- Materials not available

- Lack of experience
- Not to keep pace with development, lack of the desire for development.

\section{Acknowledgment}

Acknowledgments to all Iraqi professors and architects and civilians engineers, who are shared their experience in this survey and practical study of this search.

\section{References}

1 W. Carry "Red Bus Lane Treatment Evaluation", Institute of Transportation Engineers Annual Meeting and Exhibit, California (2012).

2 M. Birk, R. Burchfield, J. Flecker "Improved Safety through Enhanced Visibility". City of Portland, Office of Transportation, Oregon, (1999).

3 http://www.asphacolor.com/index_main.html.

4 S. Varamini, Technical, Economic and Environmental Evaluation, of Warm Mix Asphalt and Coloured Asphalt for Usage in Canada, Doctor thesis, Civil Engineering, Waterloo, Ontario, Canada, 32 (2016).

5Alternative Paving Concepts Inc. "Street Print Making Asphalt Beautiful".

http://www.alternativepaving.com/downloads/Product_Overvie w.pdf

6 http://asphaltcementprinting.com/questions/index.html

7What is Street Print.

http://www.asphalt-

impressions.co.za/what\%20is\%20streetprint.htm.

8 Ibid. 5

9 Asphalt Applications. Construction and Surfacing of Footways and Cycle Ways Using Asphalt, Information Sheet 11, Mineral Products Association, London, 1 (2009).

10 Blaine, "Integrated Paving Concepts, The Paving Surface Selector, a Guide to The Applications and Economics of Commercial and Municipal Grade Paving Solutions" Peace Portal.

http://www.streetprint.com/

http://asphaltcementprinting.com/publications/384.pdf 11 Ibid.

12 Mclaughlin, Mary-Beth, oncrete or Asphalt, Choice is on Surface, The Blade. All rights reserved, 2003.

http://www.toledoblade.com/Real-Estate/2003/07/20/Concreteor-asphalt-Choice-is-on-surface.print.

13 Asphalt Applications. Decorative and Coloured Finished for Asphalt Surfacing, Information Sheet 4, Mineral Products Association, London (2009).

$14 \mathrm{http}: / /$ makkahnewspaper.com/article/138757.

15 W. Frank, Colored Asphalt Is Decorating Paving Public Spaces", Asphalt Institute, Triangle logo and Asphalt magazine are all trademarks of the Asphalt Institute, 2017.

16 K.K. kawther, The Visual Image Quality for the Future City, the Engineering and Technology Journal, University of Technology, 33, 1-36, 2015.

17 Lee, H., \& Kim, Y. Laboratory Evaluation of Color Polymer concrete Pavement with Synthetic Resin Binder for Exclusive Bus Lanes. Transportation Research Record (1991), (2007).

18. S. Varamini, M. Farashah S. L. Tighe, Coloured 
Asphalt Bus Rapid Transit Lanes in The Regional Municipality of York: Integrating Laboratory Performance Testing Into Sustainable Pavement Asset Management, Resilient Infrastructure, (2016).

19http://www.mbc.net/ar/programs/mbc-news/articles/ 2012/9/12.

20 Asphalt Applications, Construction and surfacing of car parking areas including private drives, Information Sheet 1, Mineral Products Association, London, (2009).

21. K. K. kawther, M.Sc. thesis, University of Technology, (2014).

22. NACTO, Urban Street Design Guide, National Association of City Transportation Officials, 2013. 